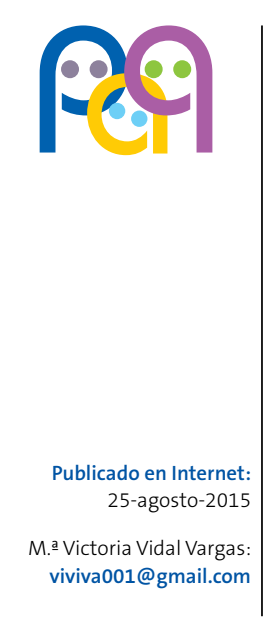

Palabras clave:

- Osteocondrosis

- Pie

- Escafoide

\title{
Dolor en el pie y cojera. Osteocondrosis del escafoides tarsiano
}

\author{
M. V. Vidal Vargas, M. B. Romero Romero, A. S. Jiménez Sarmiento, \\ M. Rodríguez-Piñero Durán
}

Servicio de Medicina Física y Rehabilitación. Hospital Universitario Virgen de la Macarena.

\author{
Sevilla. España.
}

El concepto nosológico de necrosis ósea presupone la existencia de un trastorno circulatorio, aunque este pueda no ser anatómicamente demostrable. La multitud de términos empleados para designar esta entidad demuestra la confusión existente acerca de sus mecanismos y características; incluso el término "necrosis avascular" es erróneo, ya que los vasos siguen estando presentes: el trastorno es circulatorio (funcional), no anatómico (estructural).

El término osteocondrosis hace referencia al trastorno isquémico exclusivamente del hueso en crecimiento.

El dolor en el pie y la cojera son síntomas comunes de presentación, y cuando la osteocondrosis se localiza en los huesos del pie el diagnóstico puede ser complicado si esa enfermedad no se tiene presente.

\section{Foot pain and limp. Tarsal navicular osteochondrosis}

The nosologic concept of bony tissue necrosis presupposes the existence of a circulatory derangement,
even though this derangement may not be anatomically demonstrable. The multitude of terms used
for designating this entity just demonstrate the prevailing confusion regarding its mechanisms and
characteristics; even "avascular necrosis", is erroneous, as the vessels themselves are still present: the
derangement is a circulatory (functional), not a structural (anatomic) one.
Osteochondrosis is a term used to describe a group of disorders that affect the growing skeleton.
Foot pain and a limp are common presenting symptoms, and its diagnosis can be really challenging
when ostechondrosis is located on foot bones and this condition is not in our mind.

\section{INTRODUCCIÓN}

El concepto de osteonecrosis indica muerte de los constituyentes del hueso (osteocitos) y de la médula ósea (hematopoyética y grasa) por causa de una alteración en la vascularización.

Existe una gran confusión conceptual puesta de manifiesto en el gran número de nombres utilizados, tales como necrosis isquémica, osteocondrosis, osteocondritis, necrosis avascular, necrosis aséptica, osteonecrosis, necrosis idiopática ${ }^{1}$.

El término avascular es incorrecto, pues los vasos están presentes pero con su circulación comprometida, produciéndose cese o reducción del aporte sanguíneo a esa área. Sería alteración funcional, no anatómica. 
La etiopatogenia actualmente sigue sin ser del todo conocida. Los factores etiológicos que se implican son: fuerzas de compresión repetidas, microtraumatismos, calzado, alteraciones en la biomecánica de la marcha en sus distintas fases y uso excesivo; también están involucradas enfermedades endocrinas y vasculopatías. En cualquier caso, terminan produciéndose vasoespasmo y alteraciones en los vasos arteriales que llevan al hueso a sufrir isquemia.

La osteocondrosis hace referencia a enfermedad isquémica autolimitada, en las apófisis, epífisis y huesos cortos del hueso inmaduro. Se trata pues, de un proceso patológico que afecta a hueso joven, en crecimiento, en su centro de osificación; con un trastorno vascular como causa común. El hueso en crecimiento tiene menor capacidad de respuesta para soportar sobrecarga o agresión, produciéndose secundariamente lesión isquémica.

En todos los casos, con independencia de la edad, existe una fase inicial, que se caracteriza por la muerte celular tanto del hueso como de la médula ósea ${ }^{1}$. En el adulto, la evolución biológica natural de la necrosis se dirige hacia la alteración estructural por colapso y fracaso del proceso reparador con el consiguiente desarrollo de artrosis secundaria. En el niño, la gran diferencia respecto al adulto estriba en el hecho de que el núcleo de osificación se encuentra envuelto por el cartílago de crecimiento epifisario que se nutre del líquido sinovial; así el proceso reparador culmina con la reosificación del núcleo.

Las osteocondrosis ${ }^{2}$ más frecuentes se localizan en la columna (enfermedad de Scheuermann), la cadera (enfermedad de Perthes), la rodilla (enfermadades de Osgood-Schlatter, Sinding-Larsen y Blount) y el pie (enfermedad de Sever, referido al núcleo de osificación posterior del calcáneo y Khöler I, referido al escafoides tarsiano, entre otros). La osteocondrosis del escafoides tarsiano ocurre entre los tres y los siete años de edad; es seis veces más frecuente en varones y es unilateral en el $75-80 \%$ de los casos $^{3}$.

Todas las osteocondrosis que afectan al miembro inferior se pueden presentar clínicamente con dolor y cojera, habitualmente sin trauma previo ni causa que lo explique 4 .

El objetivo de este artículo es describir la osteocondrosis del escafoides tarsiano en niño con cojera de larga evolución.

\section{CASO CLÍNICO}

Niño varón de cinco años que acude a consulta de Rehabilitación derivado por el pediatra de Atención Primaria con motivo de cojera de cuatro meses de evolución. La madre refiere haber consultado al pediatra en varias ocasiones por inflamación en pie derecho y cojera, que han impedido al niño realizar juegos y otras actividades propias de su edad. Aunque también cuenta que desde hace 2-3 semanas lo encuentra mejor.

\section{Exploración}

- En descarga: edema y dolor a la palpación sobre cara interna de mediopié derecho (cuña medial y escafoides tarsiano).

- Marcha: línea de progresión del paso neutra, con ligera claudicación del miembro inferior derecho.

- Huella plantar: pies cavos grado 1, con valgo fisiológico para la edad.

- Sin alteraciones rotacionales ni de alineación de miembros inferiores.

- No hay dismetría en decúbito.

- Raquis: eje centrado, Adams negativo.

Para no demorar el tratamiento y por sospecha clínica, solicitamos con carácter urgente radiografías anteroposterior y lateral de ambos pies y observamos aumento de densidad ósea, aplanamiento anteroposterior del escafoides (Fig. 1) y forma de moneda o lente bicóncava en proyección lateral (Fig. 2), manteniéndose constante la distancia entre astrágalo y cuña; todas ellas características radiológicas de osteocondrosis de escafoides tarsiano o enfermedad de Khöler I. 


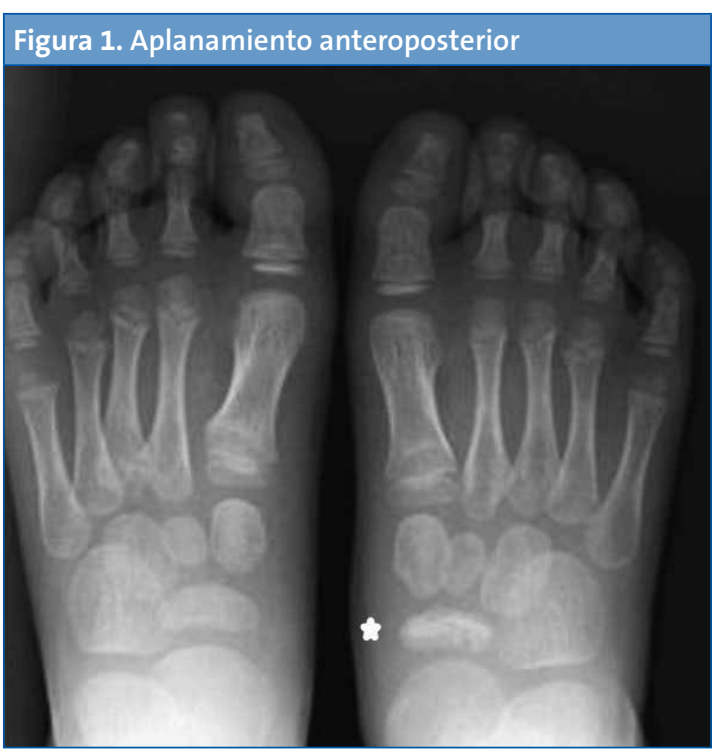

\section{Tratamiento}

En general se recomienda reposo variable, según clínica y tiempo de evolución, analgésicos y/o antiinflamatorios y ortesis plantar con mantenimiento del arco longitudinal medial, que ayuda a la descarga del escafoides, ya que este queda en el punto más elevado del arco plantar medial.

\section{DISCUSIÓN}

El concepto de osteocondrosis siempre hace referencia al hueso en crecimiento, pudiéndose producir en apófisis, epífisis o centros de osificación. Con

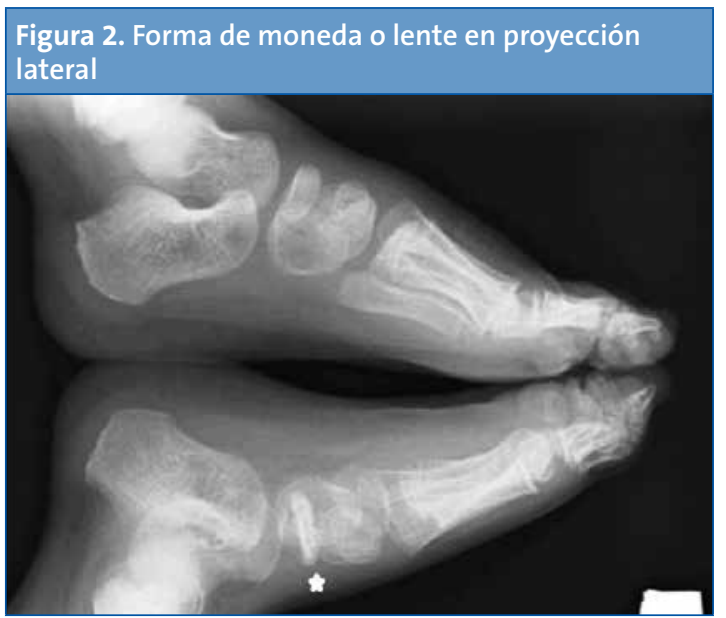

carácter general, las osteocondrosis suelen ser procesos benignos y autolimitados en el tiempo (4-7 meses), pero la resolución radiológica puede tardar más de 12 meses.

La cronología de la osificación del pie es como sigue: al nacer, astrágalo, calcáneo, cuboides, metatarsianos y falanges; a los tres meses, tercera cuña; el último núcleo primario en osificarse es el escafoides (4-5 años). Los sesamoideos se osifican a los ocho años y la apófisis del quinto metatarsiano y la tuberosidad posterior del calcáneo a partir de los ocho años.

Así pues, en cada edad hay que pensar en una localización diferente posible de osteocondrosis, las cuales acuñan el nombre propio del autor que las describió por primera vez ${ }^{1}$ : Sever (tuberosidad posterior del cacáneo) a los 8-15 años; Köhler I (escafoides tarsiano) a los 3-8 años; Iselin (apófisis base del quinto metatarsiano) a los 8-17 años; Renander (sesamoideos) a los 9-17 años; Thiemann (epífisis de la falanges) a los 12-18 años; Freiberg o Köhler II (cabeza de metatarsianos) a partir de los 14 años.

El cuadro clínico de dolor en los pies y la cojera sin causa aparente es un problema relativamente frecuente en niños y adolescentes y puede estar ocasionado por una osteocondrosis en alguna parte del esqueleto del miembro inferior.

En niños y adultos jóvenes con cojera y dolor unilateral en extremidad inferior sin trauma previo, que no cede en un tiempo de 2-3 semanas, debemos solicitar radiografías comparadas con prioridad y pensar en una osteocondrosis como probabilidad diagnóstica.

Aunque la osteocondrosis del pie suele ser benigna y autolimitada, con resolución habitualmente completa, su diagnóstico temprano nos permite acortar el periodo nada despreciable de dolor en el niño y de limitación en sus actividades, así como la preocupación y ansiedad secundaria que esto ocasiona a los padres.

\section{CONFLICTO DE INTERESES}

Los autores declaran no presentar conflictos de intereses en relación con la preparación y publicación de este artículo. 


\section{BIBLIOGRAFÍA}

1. Carranza-Bencano A, Fernández-Torres JJ, del CastilloBlanco G, Alegrete-Parra A, Fernández-Velázquez R. Necrosis avasculares de los huesos del pie. En: Revista del pie y tobillo [en línea] [consultado el 22/07/2015]. Disponible en http://pieytobilloonline. com/images/stories/contenido/Descargas/09mayo.pdf
2. Atanda A, Shah SA, O'Brien K. Osteochondrosis: common causes of pain in growing bones. Am Fam Physician. 2011;83:285-91.

3. Shastri N, Olson L, Fowler M. Kohler's disease. West J Emerg Med. 2012;13:119-20.

4. Kose O, Demiralp B, Oto $M$, Sehirlioglu A. An unusual cause of foot pain in a child: osteochondrosis of the intermediate cuneiform. J Foot Ankle Surg. 2009;48: 474-6. 